\title{
Kinesin-Like Protein KIF20A
}

National Cancer Institute

\section{Source}

National Cancer Institute. Kinesin-Like Protein KIF20A. NCI Thesaurus. Code C126524.

Kinesin-like protein KIF20A (890 aa, 100 kDa) is encoded by the human KIF20A gene.

This protein is involved in both intracellular protein transport and cell division. 